\title{
Deep Brain Stimulation Hardware Infections: A Case Series
}

\author{
Hulagu Kaptan ${ }^{1 *}$, Furkan Yuzbasi ${ }^{1}$, Fatih Özturk ${ }^{2}$, Haluk Vayvada ${ }^{1}$ \\ ${ }^{1}$ Dokuz Eylül University, Department of Neurosurgery, Izmir, Turkey; ${ }^{2}$ Dokuz Eylül University, Department of Plastic \\ Reconstructive and Aesthetic Surgery, Izmir, Turkey
}

Edited by: Mirko Spirosk Citation: Kaptan H, Yuzbasi F, Özturk F, Vayvada H. Deep Brain Stimulation Hardware Infections: A Case Series. Open Access Maced J Med Sci. 2020 Sep 15; 8(C): $172-176$ https://doi.org/10.3889/oamjms.2020.5530 ${ }^{*}$ Correspondence: Hulagu Kaptan. Dokuz Eylü University, Department of Neurosurgery, Izmir, Turkey. E-mail: hulagukaptan@yahoo.com Received: 15-Jan-2020 Revised: 20-Jan-2020 Accepted: 21-Feb-2020 Copyright: ๑ 2020 Hulagu Kaptan, Furkan Yuzbasi, Funding: This research did not receive any financial Competing Interests: The authors have declared that no competing interest Open Access: This is an open-access article distribute under the terms of the Creative Commons AttributionNonCommercial 4.0 International License (CC BY-NC 4.0)

\section{Objective}

Deep brain stimulation (DBS), which replaces thalamotomy, is a safe treatment method used for the treatment of Parkinson's disease, tremor, dystonia, and some psychiatric disorders. As in almost every implantation surgery, DBS also has some specific complications [1], [2].

The most common complications of DBS surgery are hardware complications. Among these hardware infections and surgery area, erosions have special conditions [3], [4]. Some authors evaluate wound erosions as a complication independent from infection, while some others associate it with infection [5], [6], [7]. Due to this difference, infection rates have been reported between $0 \%$ and $23 \%$ in the DBS series [7], [8], [9], [10], [11].

In the treatment of hardware infections, system removal is being considered in cases not responding to antibiotherapy [12], [13]. Temel et al. reported that antibiotherapy achieves up to $50 \%$ success in hardware infections, and system removal can control infection more effectively [14]. It becomes more challenging to reach a solution with medical treatment in the presence of persistent wound erosion associated with hardware infection, and sometimes, there is a need for wound revision. And finally, the process may end with system removal. However, this is an important problem, especially for patients who have significant benefits from DBS implantation, and the removal of the system can lead to depressive disorders [4].

In this study, we would like to discuss different aspects of hardware infections and contribute to the literature by presenting our treatment methods on four patients.

\section{Materials and Methods}

This study was carried out in Dokuz Eylül University Medical Faculty Hospital Neurosurgery Clinic. Four DBS cases were included in the study and a retrospective study was performed.

Bilateral subthalamic nucleus (STN-DBS) was performed in four patients due to Parkinson's Disease. The electrodes were supplied from left postauricular area and placed on neurostimulator subclavicular area. The lead was removed from the left postauricular region. The neurostimulator was implanted in the subclavicular area. The same medical device brand was used for all cases, and there were no pre-operative complications.

Patients had not hypertension or any other comorbidities such as cancer. Only one patient had diabetes mellitus (Table 1). 
Table 1: Features of cases

\begin{tabular}{|c|c|c|c|c|}
\hline Features & Case - 1 & Case -2 & Case -3 & Case -4 \\
\hline Age & 53 & 62 & 64 & 61 \\
\hline Gender & $\mathrm{F}$ & $\mathrm{F}$ & M & M \\
\hline Disease & PD & PD & PD & $\mathrm{PH}$ \\
\hline Surgery & Bilateral STN & Bilateral STN & Bilateral STN & Bilateral STN \\
\hline Beginning of infection & $3^{\text {rd }}$ month & $4^{\text {th }}$ month & $1^{\text {st }}$ month & $3^{\text {rd }}$ month \\
\hline Number of wound site revision & 6 & 2 & - $\quad$ & 1 \\
\hline Pathogen & Pseudomonas aeruginosa & - & - & Coagulase negative Staphylacoccus \\
\hline Infection region & Extension cables + PG & Extension lead & PG & Extension lead \\
\hline Therapy & Surgery + antibiotherapy & Surgery+antibiotherapy & Puncture+ antibiotherapy & Surgery + antibiotherapy \\
\hline Antibiotics & Cefepime + Ciprofloxacin & Ampicillin and Sulbactam & Ampicillin and Sulbactam & Ampicillin and Sulbactam + Ciprofloxacin \\
\hline Explantation of system & Yes & No & No & No \\
\hline
\end{tabular}

\section{Results}

\section{Case - 1}

A 53-year-old female patient with Parkinson's Disease was implanted DBS to bilateral STN. She was suffering from diabetes mellitus and was using oral antidiabetic. In the post-operative follow-up, it was observed that the patient had a significant benefit and that she started performing her old habit of knitting. In the post-operative $3^{\text {rd }}$ month, there was surgical site erosion on the left frontal incision, and the lead was protruded from skin (Figure 1). Hence, IV antibiotherapy and surgical site revision were performed to the patient, and the lead was transported to the subcutaneous tissue. In the post-operative $13^{\text {th }}$ month (Figure 2), surgical site erosion was observed on the left postauricular incision, and the lead was protruded from skin, and there was liquid discharge on the right frontal side. Pseudomonas aeruginosa growth was determined in the sample which taken from wound discharge. Removing of DBS system was offered to the patient, but she did not accept the offer due to high benefits she got from the device, and her condition was good. On this, she received IV antibiotherapy, and then, surgical site revision was performed, and the lead was transported to the subcutaneous tissue again. In the post-operative $14^{\text {th }}$ month, the patient was followed up with IV antibiotics on the development of purulent discharge on the postauricular region. In the post-operative $16^{\text {th }}$ month, wound site revision was performed by taking the leads from postauricular region to the suboccipital fascia. In the post-operative $18^{\text {th }}$ month, surgical site erosion was observed on the left postauricular incision, and the lead was protruded from the skin. For that reason, wound site revision was performed. In the post-operative $20^{\text {th }}$ month, neurostimulator on the left supraclavicular region was removed due to wound site erosion. Left supraclavicular region wound was debrided, the leads were transported right postauricular region, and neurostimulator was placed to the right supraclavicular region. Due to the right supraclavicular region erosion and protrusion of neurostimulator, DBS system was removed. During the management of the process, it was cooperated with the Plastic Surgery and Infectious Diseases departments.

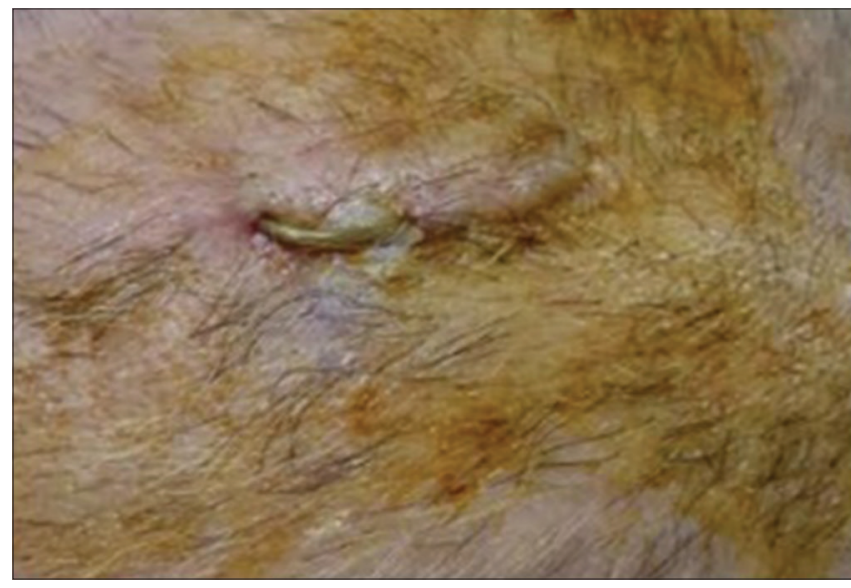

Figure 1: Surgical site erosion in left frontal region and protruded lead from skin

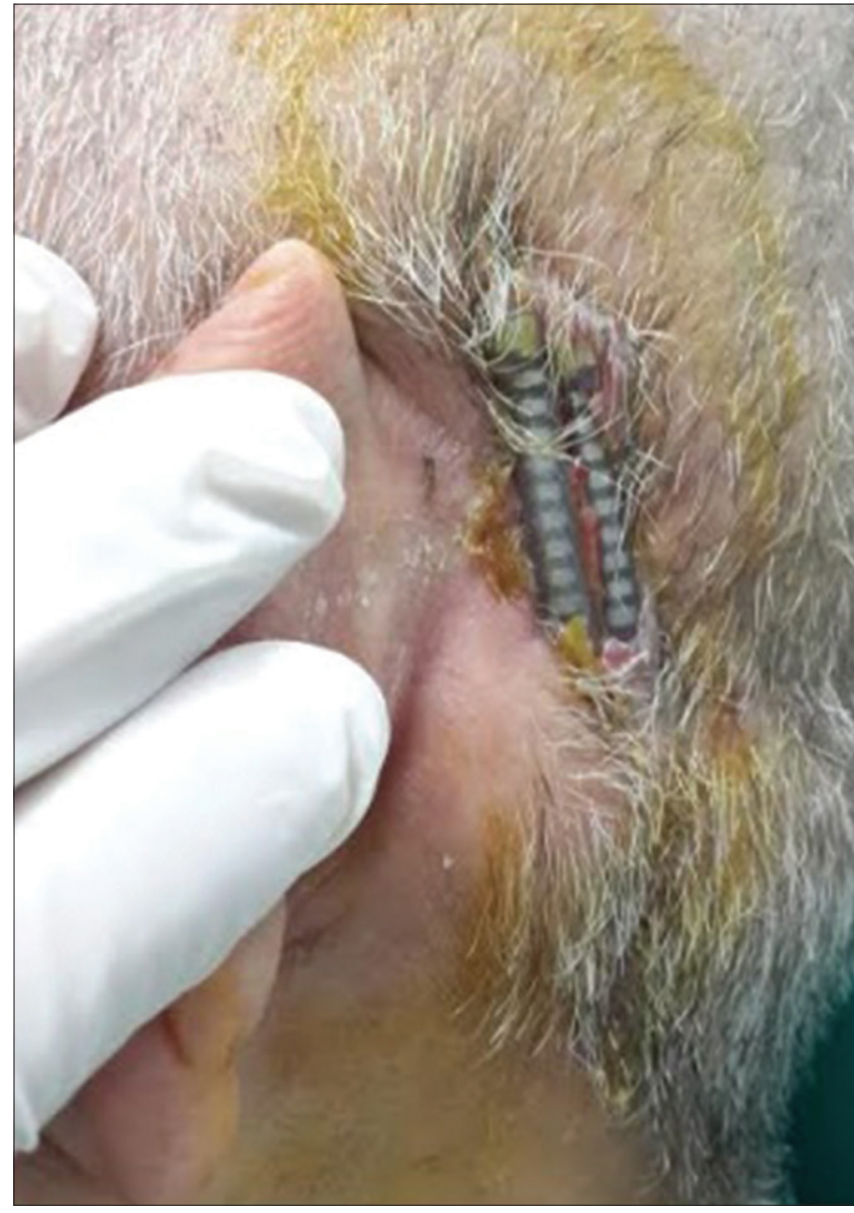

Figure 2: Surgical site erosion in left postauricular region and protruded lead from 
During this process, clinical findings of widespread or central nervous system infection were never observed. Laboratory values were within normal values, and there was no encephalitis sign in radiological studies. The patient did not allow removal of DBS system until the $22^{\text {nd }}$ month of the operation despite all surgical site revisions and long-term hospitalizations for IV antibiotherapy.

\section{Case - 2}

A 62-year-old female patient with Parkinson's disease was implanted DBS to bilateral STN. In the post-operative $4^{\text {th }}$ month, there was surgical site erosion on the left postauricular incision, and the lead was protruded from the skin. Hence, IV antibiotherapy and surgical site revision were performed on the patient, and the lead was transported to the subcutaneous tissue. No agent was determined in the sample which was taken from the wound. Clinical findings and laboratory values of widespread or central nervous system infection were never observed. The patient who completed the $1^{\text {st }}$ year of her operation is followed up as an outpatient without any problem.

\section{Case - 3}

A 64-year-old male patient with Parkinson's disease was implanted DBS to bilateral STN. In the post-operative $1^{\text {st }}$ month, swelling and erythema occurred in the subclavicular region. The swelling was drained (50cc) with a puncture using USG guidance. Microbiologic and empirical antibiotherapy were started. No microbiological agent was determined in the sample. The patient who had not repeated swelling after the treatment has been followed as outpatient.

\section{Case -4}

A 61-year-old male patient with Parkinson's disease was implanted DBS to bilateral STN. In the post-operative $3^{\text {rd }}$ month, there was surgical site erosion on the left postauricular incision, and the lead was protruded from the skin (Figure 3). Coagulasenegative staphylococcus was detected in the patient's wound culture, and IV antibiotherapy was started. The patient, whose wound erosion was treated, is followed up as outpatient without any problem.

\section{Discussion}

As the number of the centers applying DBS implantation increases, the research papers

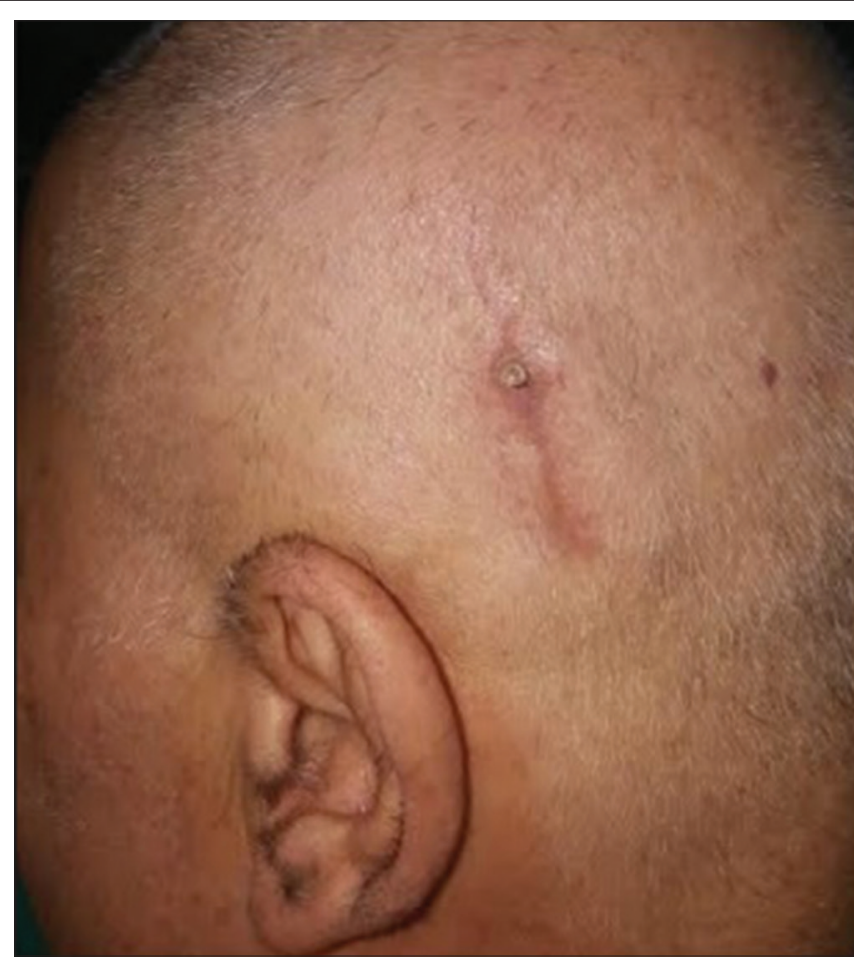

Figure 3: Surgical site erosion in left postauricular region and protruded lead from skin

concerning device-related infections start to take part in the literature. Tolleson et al. have taken into account the presence of epidermal erosions and infections regarding post-operative first 30 days and have found that previous presence of scalp erosion, the longer duration of the operation, and the presence of more people in the operation room is among the risk factors of a delayed infection [10]. In another study, the young age is described as a risk factor for the development of infection [15]. Immunity suppressing illnesses are potential risk factors for device-related infections [16]. In studies, no relation was found between the development of the infection and demographical data of the patients and indications of DBS implantation [4], [12], [17].

$\mathrm{Kim}$ et al. determined infection ratio as $7 \%$ in series that included 169 cases with Parkinson's disease and implanted DBS. $75 \%$ of infections occurred during the first 3 months after operation. According to study results, as surgical profilaxy $1^{\text {st }}$ generation cephalosporins were offered in 6 days after the operation due to their Gram-positive effect [18]. In our study, $75 \%$ of the infections occurred in the first 3 months after DBS, and ampicillin/sulbactam profilaxy was applied during the first 10 days.

In our study, Pseudomonas was isolated in one female patient, and no cause was identified in other two. In a study with wider population, the most common isolated cause among men was Coagulasenegative staphyloccocus, and among women were Methicillin-Susceptible Staphylococcus aureus and $P$. aeruginosa [19]. The data did suggest that intrawound VP may help to reduce the SSI risk after 
DBS implantation [3]. However, in this study, Grampositive bacteria were the most common pathogens (75\%). Infection after DBS surgery was associated with short-term use of prophylactic antibiotics therapy. The antibiotherapy is given according to the isolated organism; and in our cases, 6-8 weeks of antibiotherapy was given. Removal of the DBS system also appears to be another treatment option with antibiotherapy. Patients benefited from the implantation do not consent for the system removal. Removal of the implantation and replantation at a future date for a complication which could be resolved through recent medical treatment options creates a huge impact on cost.

In three of our four cases, we found positive results with wound site revision and antibiotherapy. In our study, a resistant surgical site infection was developed in one patient. Although she received a longterm antibiotic treatment and had six operations for surgical wound revision, she did not consent for device removal given that she significantly benefited from DBS. Increased incidence of wound complications in surgical patients with diabetes mellitus is a well-known condition. It can be thought that diabetes disease contributes to the negativities in this patient. Despite all studies, it was not clearly defined why some patients experience DBS-related infections and erosions on surgical site, while some others do not. In our opinion, the quality and thickness of scalp take a role in the development of surgical site erosion and device-related infections. In patients with poor scalp quality and thickness placing the microcatheter beneath, the galea and fascia could be considered. All patients were shaved before surgery. We believe that this application is effective in preventing infection as well as the use of antibiotics prophylaxis (ampicillin and sulbactam) before and after the surgery.

\section{Conclusion}

We consider that antibiotic therapy can be considered as an option in such situations before the removal of DBS system. In cases which are unresponsive to wound revision and have long-term antibiotherapy and/or developed central nervous system infection, we consider that removal of DBS system may be a right choice. New multicentral studies are needed for therapeutic protocols, improving new perspectives of infections of DBS implantations, and surgical site erosions.

\section{References}

1. Kaptan H, Çakmur R. Technical case report of deep brain stimulation: Is it possible single electrode reach to both of subthalamic nucleus and ventral intermediate nucleus in one stage? Open Access Maced J Med Sci. 2018;6(4):659-62. https://doi.org/10.3889/oamjms.2018

PMid:29731935

2. Kaptan H, Ekmekci H. Long-term results for single electrodeguided deep brain stimulation used to treat Parkinson's disease. Arch Neuropsychiatry. 2019;56:1-4. https://doi.org/10.29399/ npa.23090

3. Abode-lyamah KO, Chiang HY, Woodroffe RW, ParkB, JareczekFJ, Nagahama $\mathrm{Y}$, et al. Deep brain stimulation hardware-related infections: 10-year experience at a single institution. J Neurosurg. 2018;130:1-10. https://doi.org/10.3171/2017.9.jns1780

PMid:29521584

4. Brandmeir N, Nehrbass E, Mclnerney J. An analysis of scalp thickness and other novel risk factors for deep brain stimulator infections. Cureus. 2016;8(9):e792. https://doi.org/10.7759/ cureus.792Error! Hyperlink reference not valid.

PMid:27774360

5. Bjerknes S, Skogseid IM, Sæhle T, Dietrichs E, Toft M. Surgical site infections after deep brain stimulation surgery: Frequency, characteristics and management in a 10-year period. PLoS One. 2014;9(8):e105288. https://doi.org/10.1371/journal. pone.0105288Error! Hyperlink reference not valid.

PMid:25122445

6. Chou YC, Lin SZ, Hsieh WA, Lin SH, Lee CC, Hsin YL, et al. Surgical and hardware complications in subthalamic nucleus deep brain stimulation. J Clin Neurosci. 2007;14(7):643-9. https://doi.org/10.1016/j.jocn.2006.02.016 PMid: 17532500

7. DoshiPK.Long-term surgical and hardware-related complications of deep brain stimulation. Stereotact Funct Neurosurg. 2011;89(2):89-95. https://doi.org/10.1159/000323372

PMid:21293168

8. Constantoyannis C, Berk C, Honey CR, Mendez I, Brownstone RM. Reducing hardware-related complications of deep brain stimulation. Can J Neurol Sci. 2005;32(2):194-200. https://doi.org/10.1017/s0317167100003966 PMid:16018154

9. Sillay KA, Larson PS, Starr PA. Deep brain stimulator hardwarerelated infections: Incidence and management in a large series. Neurosurgery. 2008;62(2):360-7. PMid: 18382313

10. Tolleson C, Stroh J, Ehrenfeld J, Neimat J, Konrad P, Phibbs F. The factors involved in deep brain stimulation infection: A large case series. Stereotact Funct Neurosurg. 2014;92(4):227-33. https://doi.org/10.1159/000362934

PMid:25096381

11. Voges J, Waerzeggers $Y$, Maarouf $M$, Lehrke R, Koulousakis $A$, Lenartz D, et al. Deep-brain stimulation: Long-term analysis of complications caused by hardware and surgery experiences from a single centre. J Neurol Neurosurg Psychiatry. 2006;77(7):868-72. https://doi.org/10.1136/jnnp.2005.081232 PMid: 16574733

12. Bhatia S, Zhang $\mathrm{K}$, Oh M, Angle C, Whiting D. Infections and hardware salvage after deep brain stimulation surgery: A single-center study and review of the literature. Stereotact Funct Neurosurg. 2010;88(3):147-55. https://doi. org/10.1159/000303528

PMid:20357522

13. Boviatsis EJ, Stavrinou LC, Themistocleous M, Kouyialis AT, Sakas DE. Surgical and hardware complications of deep brain stimulation. A seven-year experience and review of the literature. Acta Neurochir (Wien). 2010;152(12):2053-62. https:// doi.org/10.1007/s00701-010-0749-

PMid:20658301 
14. Temel $\mathrm{Y}$, Ackermans $\mathrm{L}$, Celik $\mathrm{H}$, Spincemaille $\mathrm{GH}$, van der Linden C, Walenkamp GH, et al. Management of hardware infections following deep brain stimulation. Acta Neurochir (Wein). 2004;146(4):355-61. https://doi.org/10.1007/ s00701-004-0219-

PMid: 15057529

15. Gorgulho A, Juillard C, Uslan DZ, Tajik K, Aurasteh $\mathrm{P}$, Behnke $\mathrm{E}$, et al. Infection following deep brain stimulator implantation performed in the conventional versus magnetic resonance imaging-equipped operating room. J Neurosurg. 2009;110(2):239-46. https://doi.org/10.3171/2008.6

PMid:18991495

16. Fenoy AJ, Simpson RK Jr., Risks of common complications in deep brain stimulation surgery: Management and avoidance. J Neurosurg. 2014;120(1):132-9. https://doi.org/10.3171/2013.10 PMid:24236657
17. Rodriguez-Oroz M, Obeso JA, Lang AE, Houeto JL, Pollak P, Rehncrona S, et al. Bilateral deep brain stimulation in Parkinson's disease: A multicentre study with 4 years follow-up. Brain. 2005;128(10):2240-9. https://doi.org/10.1093/brain/ awh571

PMid:15975946

18. Kim MS, Jeong JS, Ryu HS, Choi SH, Chung SJ. Infection related to deep brain stimulation in patients with Parkinson disease: Clinical characteristics and risk factors. J Neurol Sci. 2017;383:135-41. https://doi.org/10.1016/j.jns.2017.10.031 PMid:29246601

19. Ying S, Zeng DN, Chi L, Tan Y, Galzote C, Cardona C, et al. The influence of age and gender on skin-associated microbial communities in urban and rural human populations. PloS One. 2015;10(10):e0141842. https://doi.org/10.1371/journal.pone PMid:26510185 